\title{
SLOSHING IMPACT PRESSURES OF ROOFED LIQUID STORAGE TANKS
}

\author{
Chizuko KURIHARA, Yoshio MASUKO \\ and Akio SAKURAI
}

\begin{abstract}
In Japan, oil storage tanks and dams were severely damaged by seismic sloshing on occasion. The authors have conducted non-linear sloshing experiments for tank models of $55 \mathrm{~cm}, 223 \mathrm{~cm}$ and $670 \mathrm{~cm}$ in diameter using a long-period large-amplitude shaking table to clarify the characteristics, especially the wave crest impact pressures acting on the flat roof surfaces of tanks.

The purposes of this paper are to present the impact pressure data and to propose a simplified estimation formula based on the data.
\end{abstract}

Keywords : non-linear sloshing, impact pressure, oil storage tank

\section{INTRODUCTION}

In Japan, oil storage tanks and dams were severely damaged by seismic sloshing on occasion. The large-scale fire of oil storage tanks during the Niigata Earthquake $(M=7.5)$ in 1964 is said to have been caused by the crude oil flowing out at a joint between a floating roof and a side wall which was broken by the impact pressure generated by sloshing ${ }^{1)}$.

It is also presumed the fire of an oil storage tank during the Nihonkai Chubu Earthquake $(M=7.7)$ in 1983 was caused by sloshing ${ }^{2}$. Also, it was reported that high sloshing waves over 5 meter were observed at tanks sited $300 \mathrm{~km}$ apart from the epicenter and acceleration of earthquake ground motion was less than 26 gal. This suggests that even an earthquake occurring far away with a small acceleration can induce large sloshing to damage a structure containing a liquid such as an oil storage tank.

Research on the estimation of the wave crest impact pressure generated by the collision of water surface against a roof-like structure was originally started by von Karman ${ }^{3)}$ and Wagner, V.H. ${ }^{4}$. Afterwards many studies have been conducted, which include, for example, experimental studies on the estimation of the uplifts acting on the floor

\footnotetext{
* Member of JSCE, Principal Research Engineer, FBR Dept., Abiko Research Laboratory, Central Research Institute of Electric Power Industry (Abikoshi, Chiba-ken, 270-11 Japan)

** Principal Research Engineer, Struct. Engrg. Sec., FBR Dept., Abiko Research Laboratory, Central Research Institute of Electric Power Industry

*** Member of JSCE, Dr. of Engrg., Manager, Planning Div., Central Research Institute of Electric Power Industry (Chiyoda-ku, Tokyo, 100 Japan)
}

systems of landing piers ${ }^{5)}$ (1) , a study on the uplift acting on roller gates ${ }^{12)}$, a study on the wave pressures of tide gates $^{13)}$, and so on.

Yamamoto $^{1)}$ and Ochi and Kobayashi ${ }^{14)}$ directly discussed the sloshing wave crest impact pressures acting on the roofs of tanks. Yoshimura, et al. ${ }^{15}$ compiled the results of the experiments conducted on LNG storage tanks according to Wagner's formula. In these studies, it is assumed that the wave crest impact pressure is proportional to the square of sloshing wave crest velocity. On the other hand, in an experimental study by $\mathrm{Asai}^{16)}$, it is reported that the wave crest impact pressure is proportional to the 1.6 th power of sloshing wave crest velocity.

The authors designed and fabricated an unprecedented large-scale long-period large-amplitude shaking table, and have conducted various experiments and analyses, in order to identify the basic characteristics of non-linear sloshing and to clarify the effect of non-linear sloshing on intra-tank structures. These results are intended to be used in the aseismic design on Liquid Metal Fast Breeder Reactors.

The present paper compiles the data concerning the sloshing wave crest impact pressures acting on tank roofs and proposes a wave crest impact pressure estimation formula, in reference to the results of the past studies mentioned above in order to be useful for the aseismic design of oil storage tanks, LNG storage tanks, etc.. Small-, mediumand large-scale models were employed to examine the scale effect on the wave crest impact pressures, because the pressure have strong non-linearity.

\section{OUTLINE OF EXPERIMENTS}

The models, experimental conditions, etc. are 
Table 1 Test Models.

\begin{tabular}{|l|l|l|l|}
\hline Scale & Small-scale & Medium -scale & Large-scale \\
\hline Shape & Rectangle & Cylinder & Rectangle \\
\hline Material & Acrylic resin & Stainless steel & Steel \\
\hline Dimensions & $\begin{array}{l}\text { Length } 55 \mathrm{~cm} \\
\text { Width } 20 \mathrm{~cm} \\
\text { Depth } 20 \mathrm{~cm} \\
\text { Roof thick. } 1.0 \mathrm{~cm}\end{array}$ & $\begin{array}{l}\text { Inner dia. } 2.23 \mathrm{~m} \\
\text { Depth } \\
\text { Roof thick. } 4.0 \mathrm{~mm}\end{array}$ & $\begin{array}{l}\text { Length } 6.7 \mathrm{~m}(6.54 \mathrm{~m})^{*} \\
\text { Width } 2.1 \mathrm{~m} \\
\text { Depth } 2.5 \mathrm{~m} \\
\text { Roof thick. } 2.5 \mathrm{~cm}\end{array}$ \\
\hline
\end{tabular}

* Length of the portion with a vertical rigid plate
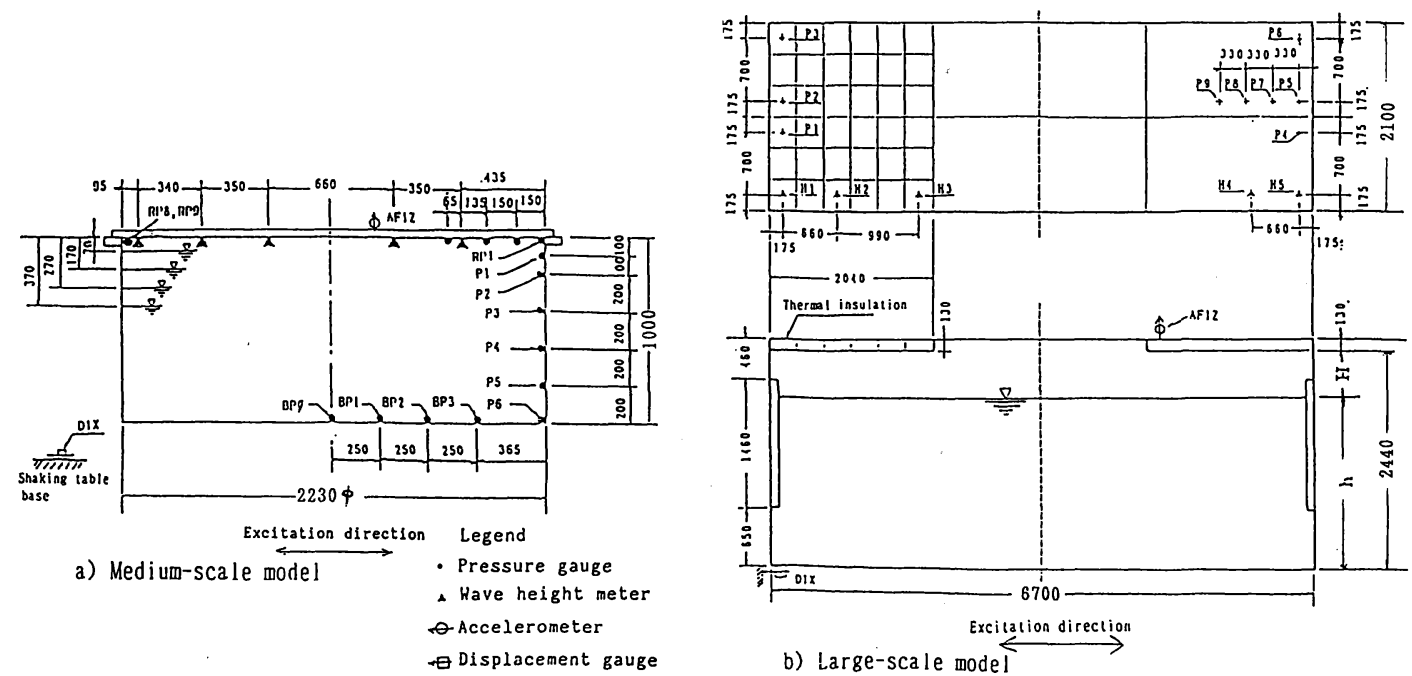

Fig.1 Measuring points and dimensional drawings.

described below.

\section{(1) Outline of models}

The models used for the experiments are summarized in Table 1.

(2) Measuring instruments and measuring points

Measuring items were pressure, wave height and acceleration, and displacement of shaking table, which were measured at the points shown in Fig.1. Pressure gauges with a maximum scale of $2 \mathrm{~kg} / \mathrm{cm}^{2}$, wave height meters with a scale range from $500 \mathrm{~mm}$ to $1000 \mathrm{~mm}$, acceleration pickups with a maximum scale of $2 \mathrm{G}$ and displacement pickups with a maximum scale of $\pm 300 \mathrm{~mm}$ were respectively used.

It is known that the water surface begins to swirl in the sloshing in a cylindrical tank, as the wave number increases. Swirling makes it difficult to measure the accurate impact pressure, since the position at which the water surface collides with the roof changes. In order to confirm whether swirling occurred, the wave height meters were installed in the circumferential direction.

\section{(3) Shaking table}

The outline and specification of the long-period large-amplitude shaking table used in the experiments are shown in Fig. 2 and Table 2.

\section{(4) Experimental conditions}

The crest velocity immediately before collision is a function of sloshing period $(T)$, displacement input $(D)$ and distance between roof and liquid surface $(H$; hereinafter called the top space height). So, as experimental parameters, $D$ and $H$ were used.

For excitation, steady sinusoidal waves (maximum 30 waves) were applied at the primary natural frequency of sloshing, to generate the crest impact pressure (Adding steady sinusoidal waves, large-scale model experiments were conducted applying the waves of Niigata Earthquake, Tokachi-oki Earthquake and Great Kanto Earthquake, and two seismic waves prepared by CRIEPI 
Side guide and safety against overturning

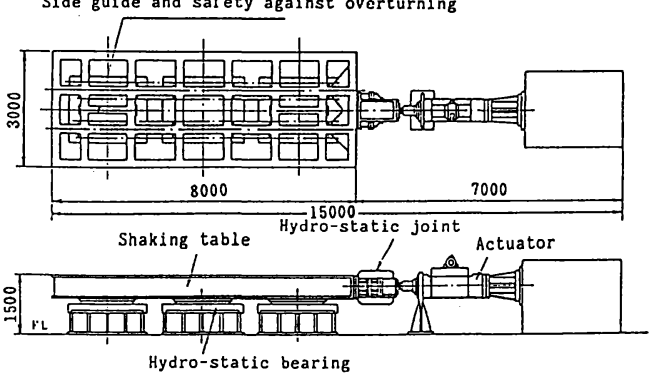

Fig.2 Long-period large-amplitude shaking table.

Table 2 Specification of long-period large-amplitude shaking table.

\begin{tabular}{|c|l|l|}
\hline Na & Item & Specification \\
\hline 1 & Dimensions of shaking table & $8 \pm 3$ m \\
\hline 2 & Maximum movable load & 100 tons \\
\hline 3 & Excitation direction & One horizontal direction \\
\hline 4 & Maximum displacement stroke & \pm 300 mm \\
\hline 5 & Maximum velocity & \pm 50 cm/s \\
\hline 6 & Maximum acceleration & $\pm 0.8 \mathrm{G}$ \\
\hline 7 & Frequency range & DC $~ 5$ Hz \\
\hline 8 & Drive method & Electrohydraulic servo control \\
\hline 9 & Control method & $\begin{array}{l}\text { Acceleration control and } \\
\text { displacement control selectable }\end{array}$ \\
\hline 12 & Permissible Yawing moment & $50 \mathrm{t}-m$ \\
\hline 11 & Excitation vaveform & $\begin{array}{l}\text { Regular uaves (sinusoidal waves) } \\
\text { Irregular waves (seismic waves. } \\
\text { Overturning moment }\end{array}$ \\
\hline
\end{tabular}

up to the limit of excitation ${ }^{18)}$. These waves are noted to comprise significant long-period components.

The experimental results showed that the sloshing was sinusoidal also in these cases, and almost the same phenomena as caused by sinusoidal wave application were confirmed ; so, the results due to sinusoidal wave excitation was chosen in the present study).

The displacement input was raised from about 1 $\mathrm{cm}$ almost by every $1 \mathrm{~cm}$ step. Experiment cases of each model (with the top space height as a parameter), and the primary resonance periods of linear sloshing are shown in Table 3.

It was confirmed that the measured values well coincided with the values calculated from the linear theory within $0.5 \%$ errors.
Table 3 Experimental conditions.

\begin{tabular}{|c|c|c|c|c|c|}
\hline \multirow{2}{*}{ Model } & \multirow{2}{*}{ Case } & \multirow{2}{*}{$\begin{array}{l}\text { Top space } \\
\text { height } \\
H(c \mathbb{s})\end{array}$} & \multirow{2}{*}{ 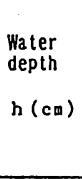 } & \multicolumn{2}{|c|}{$\begin{array}{l}\text { Primary resonance period } \\
\mathrm{T}_{0}(\text { sec. })(\text { Frequency }(\mathrm{Hz}))\end{array}$} \\
\hline & & & & $\begin{array}{l}\text { Measured } \\
\text { value }\end{array}$ & $\begin{array}{l}\text { Calculated } \\
\text { yalue }\end{array}$ \\
\hline $\begin{array}{l}\text { Small } \\
\text { scale }\end{array}$ & $\begin{array}{l}1 \\
2 \\
3\end{array}$ & $\begin{array}{l}2 \\
4 \\
6\end{array}$ & $\begin{array}{l}18 \\
16 \\
14\end{array}$ & $\begin{array}{l}0.95(1.05) \\
0.99(1.01) \\
1.03(0.97)\end{array}$ & $\begin{array}{l}0.96(1.05) \\
0.99(1.01) \\
1.03(0.97)\end{array}$ \\
\hline $\begin{array}{l}\text { Medi um } \\
\text { scale }\end{array}$ & $\begin{array}{l}1 \\
2 \\
3 \\
4\end{array}$ & $\begin{array}{l}7 \\
17 \\
27 \\
37\end{array}$ & $\begin{array}{l}93 \\
83 \\
73 \\
63\end{array}$ & $\begin{array}{l}1.64(0.61) \\
1.67(0.599) \\
1.71(0.585) \\
1.77(0.565)\end{array}$ & $\begin{array}{l}1.64(0.61) \\
1.67(0.600) \\
1.71(0.585) \\
1.77(0.565)\end{array}$ \\
\hline $\begin{array}{l}\text { Large } \\
\text { scale }\end{array}$ & $\begin{array}{l}1 \\
2 \\
3 \\
4\end{array}$ & $\begin{array}{ll}1 & 4 \\
3 & 3 \\
5 & 2 \\
7 & 1\end{array}$ & $\begin{array}{l}230 \\
211 \\
192 \\
173\end{array}$ & $\begin{array}{l}3.3(0.3) \\
3.3(0.3) \\
3.4(0.295) \\
3.5(0.286)\end{array}$ & $\begin{array}{l}3.3(0.3) \\
3.3(0.3) \\
3.4(0.294) \\
3.5(0.285)\end{array}$ \\
\hline
\end{tabular}

\section{RESULTS OF EXPERIMENTS}

\section{(1) Excitation wave number and crest impact} pressure

The largest crest impact pressure usually appears at the first wave of collision when the liquid surface is less disturbed ${ }^{16), 17)}$. Also in the experiments of this time, when the top space was wide enough, the largest crest impact pressure appeared at the 1 st or 1.5th ( $\sim 2$ nd) wave of collision (Fig.3). If the top space is wide enough, the largest impact pressure among the pressures generated within the first ten waves can be regarded to appear at the 1.5 th wave (collision at the opposite side after half the period) or the 2 nd wave.

As for the crest impact pressure distribution on a roof, the largest pressure appears at the joint between the roof and the tank side wall ${ }^{18)}$. So, the crest impact pressure measured at the edges of the roof was used for analysis.

The results of various experiments show that the largest impact pressure appears at the 1st wave of collision in the following cases :

a) When the top space is high enough (more than about $1 / 10$ of the diameter of the tank) to allow sufficient growth of sloshing wave height.

b) When the top space is higher than 3 times of the excitation amplitude.

(2) Excitation amplitude and crest impact pressure

The excitation amplitude was changed to measure impact pressures, fixing resonance frequency. Some of the results are shown in Fig.4, which indicates that if there is no structure in the model as in these experiments, a larger excitation amplitude 


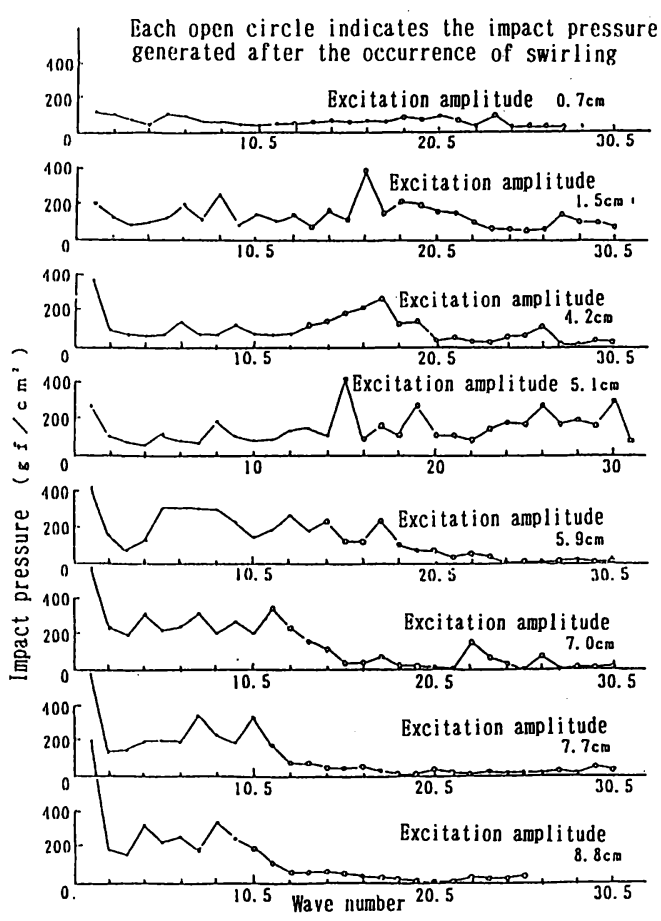

Fig.3 Relation between excitation wave number and impact pressure (medium-scale model, top space height $27 \mathrm{~cm}$ ).

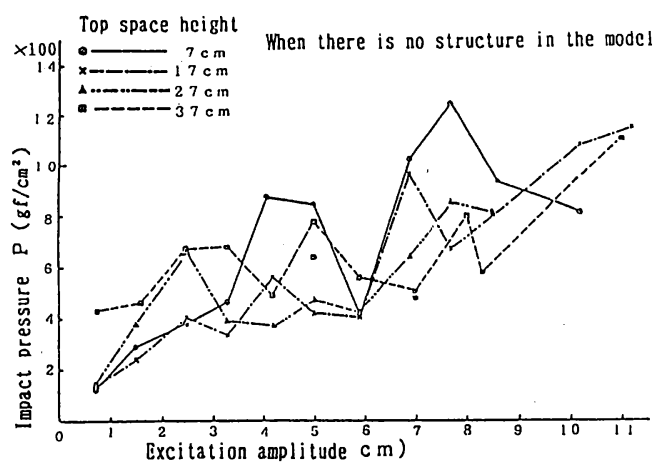

Fig.4 Relation between excitation amplitude and impact pressure (medium-scale model).

gives a higher impact pressure. (However, if there are many structures in a tank like a pool-type FBR, a larger excitation amplitude does not necessarily give a higher impact pressure.)

\section{(3) Crest impact pressure waveform}

The impact pressure waveform has several similar patterns with certain characteristics peculiar to the top space height and excitation amplitude. The impact waveforms can be reproduced under the same experimental conditions and were classified into the 8 patterns shown in Table 4.

The ratio of numbers of each waveform pattern
Table 4 Classification of impact waveforms.

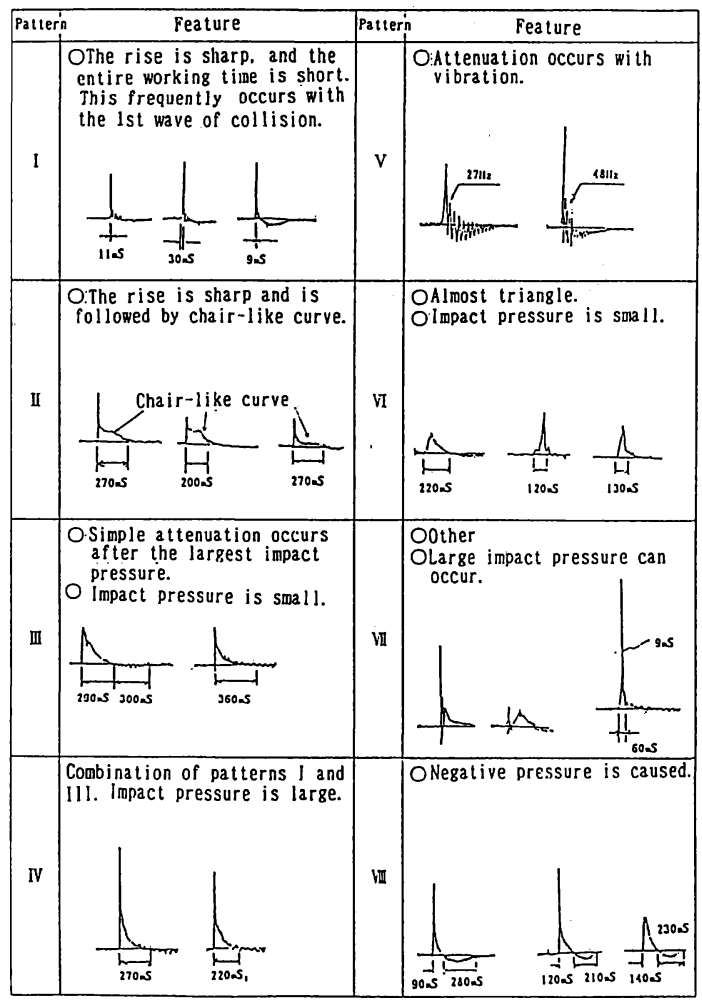

Table 5 Ratio of waveform patterns observed (\%) (medium-scale model).

\begin{tabular}{|c|c|c|c|c|c|c|c|c|c|c|}
\hline \multirow{2}{*}{$\begin{array}{c}n \\
\text { Amplityde } \\
\text { Patterñ }\end{array}$} & \multicolumn{2}{|c|}{$7 \mathrm{c} \mathrm{m}$} & \multicolumn{3}{|c|}{$17 \mathrm{~cm}$} & \multicolumn{2}{|c|}{$27 \mathrm{c} \mathrm{m}$} & \multicolumn{2}{|c|}{$37 \mathrm{c} \mathrm{m}$} & \multirow{2}{*}{$\begin{array}{l}\text { Remarks } \\
\text { (fcature) }\end{array}$} \\
\hline & $7.6 \mathrm{~cm}$ & $1.6 \mathrm{~cm}$ & $8.7 \mathrm{~cm}$ & $5.1 \mathrm{~cm}$ & $1.5 \mathrm{~cm}$ & $8.8 \mathrm{~cm}$ & $1.6 \mathrm{~cm}^{\circ}$ & $8.8 \mathrm{~cm}$ & $1.6 \mathrm{~cm}^{9}$ & \\
\hline 1 & 0 & 0 & 2 & 1 & 1 & 6 & 2 & 3 & 2 & \\
\hline II & 0 & 24 & 6 & 22 & 4 & 17 & 0 & 0 & 0 & Cha ir-like \\
\hline UII & 0 & 2 & 48 & 31 & 0 & 33 & 15 & 21 & 39 & \\
\hline $\mathrm{N}$ & 0 & 12 & 21 & 4 & 3 & 19 & 15 & 12 & 25 & \\
\hline v & 4 & 10 & 0 & 5 & 41 & 8 & 31 & 2 & 11 & Viuration \\
\hline v & 54 & 2 & 15 & 15 & 34 & 11 & 15 & 5 & 3 & \\
\hline Vo & 42 & 50 & 8 & 22 & 17 & 6 & 22 & 26 & 20 & Other \\
\hline
\end{tabular}

* Negative pressure occurred in $53 \%$ of cases.

* Negative pressure occurred in 100\% of cases.

observed for respective top space heights and excitation amplitudes are shown in Table 5.

This table indicates the following features of the respective waveform patterns.

a) The waveform with a sharply rising large pressure (pattern I ) hardly appears if the top space is narrow.

b) The "chair-like" waveform (pattern II ) never appears for any magnitude of excitation amplitude if the top space is large $(H=37 \mathrm{~cm})$.

c) The vibrating impact pressure waveform (pattern V) dominantly appears for any size of top space if the excitation amplitude is small.

d) If the top space is narrow, irregular waveforms (patterns Vland VII) increase. 


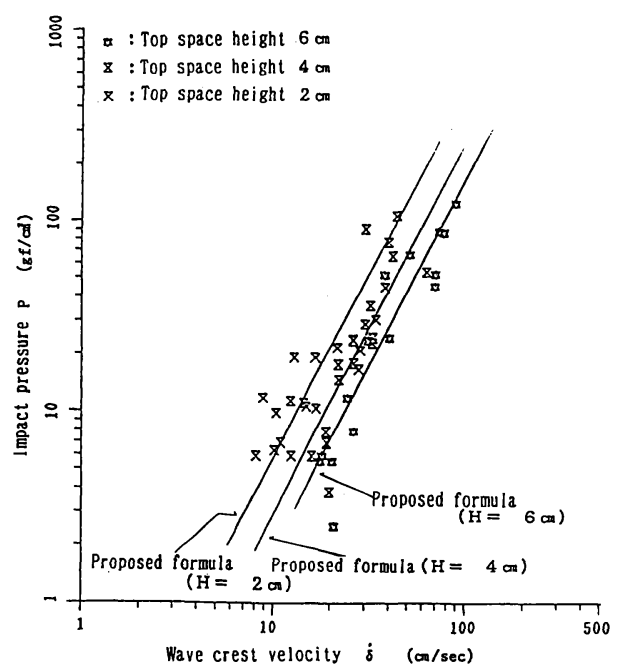

Fig.5 Relation between wave crest velocity and impact pressure (small-scale model).

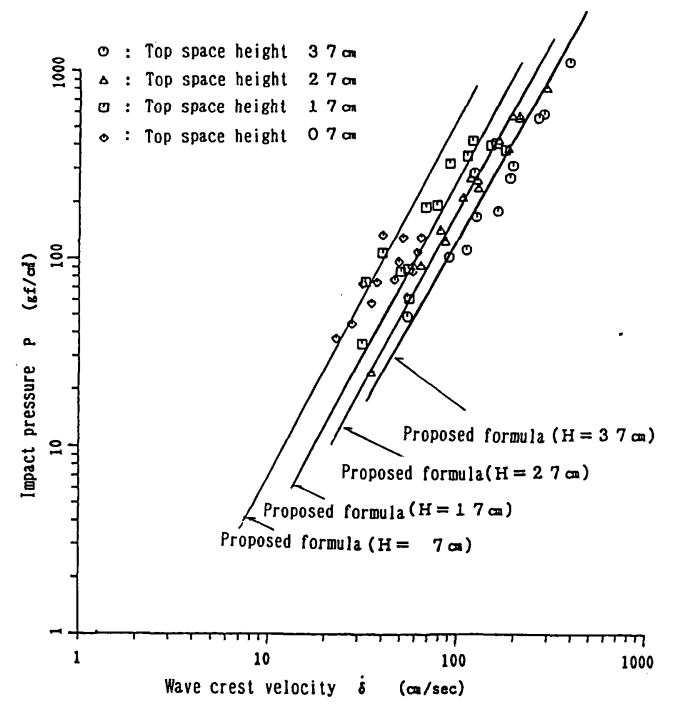

Fig.6 Relation between wave crest velocity and impact pressure (medium-scale model).

e) "Negative pressures" seldom appear when the top space is narrow.

(4) Colliding wave crest velocity and crest impact pressure

Wave height meters were used to measure the wave crest velocity. From the time-series wave heights measured 30 to $40 \mathrm{msec}$. before the collision of the liquid surface against the roof, the average rate of wave height increase was calculated to obtain the wave crest velocity.

Fig.5 $\sim 7$ show the relations between the sloshing colliding wave crest velocities and impact pressures measured in the experiments of small-, medium-

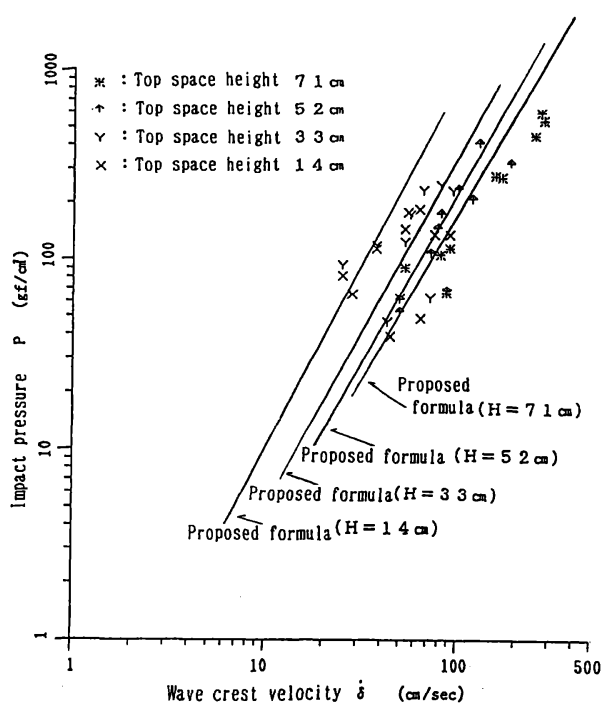

Fig.7 Relation between wave crest velocity and impact pressure (large-scale model).

and large-scale models with changing top space heights.

\section{DISCUSSION OF WAVE CREST IM- PACT PRESSURE ESTIMATION FORMULA}

Based on the results of the above experiments, the relation between wave crest velocity and wave crest impact pressure is discussed below.

(1) Impact pressure acting on a flat roof

The impact pressure generated by a moving liquid is equal to a value obtained by differentiating the momentum of the liquid by time.

In Fig.8, it is assumed that the wave height goes up to $\delta$ from the roof position if it were not for any roof. The length of the roof in contact with liquid, $r$, is expressed as follows, since the primary mode of sloshing has almost a cosine shape.

$$
r=\frac{2 R}{\pi} \cos ^{-1}\left(\frac{H}{H+\delta}\right)
$$

where, $\quad R$ : Radius of the tank $(1 / 2$ of the typical length in the case of a rectangular model)

\section{$H$ : Top space height}

Regarding the evaluation of the effective mass of the liquid colliding with the $r$ portion, the conventional studies ${ }^{1,14) \sim 18}$ adopted the mass in a quarter of a circle defined by the contact length (rather different from the above $r$ ). However, the present experimental results arranged according to this assumption showed differences of about twice between the calculated and observed ones. So, the experimental results were discussed based on the 


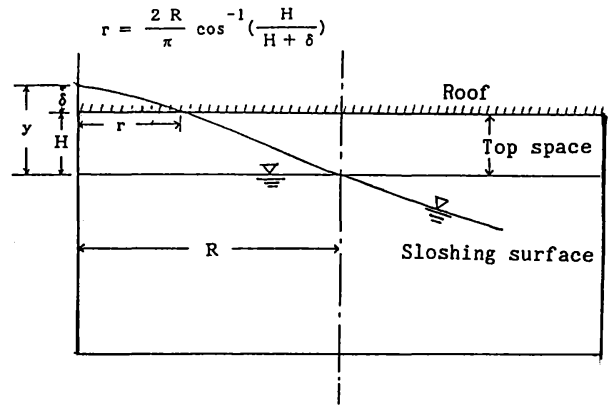

Fig.8 Typical view for discussing the impact pressure.

\section{following assumption.}

The mass per unit width of the liquid acting on the $r$ portion, $M$, is approximately considered as the virtual mass of a tank (a liquid storage tank of $H+h$ in diameter and $r$ in liquid level) with free surface. In this case, the virtual mass $M$ can be approximated by the following equation ${ }^{22,23)}$ (The liquid contact length $r$ was assumed to be smaller than the diameter).

$$
M=\frac{\rho}{g} \cdot \chi(H+h) r
$$

where $\chi$ is approximated by the following equation.

$$
\chi=\frac{0.875}{1+\frac{H+h}{2 r}}
$$

where, $\rho$ : Density of the liquid

$$
\begin{aligned}
& g \text { : Acceleration of gravity } \\
& h \text { : Liquid depth }
\end{aligned}
$$

Hence, the momentum per unit width of the liquid colliding with the $r$ portion, $F$, is

$$
F=\frac{\rho}{g} \cdot(1.75(H+h)) \frac{r^{2}}{2 r+H+h} \dot{\delta}
$$

where $\dot{\delta}$ is the wave crest velocity.

If this momentum of liquid is differentiated by time, considering equation (1), the impact pressure acting on the tank roof per unit area, $P$, can be obtained.

$$
\begin{aligned}
& P=\frac{d F}{d t} / r=\frac{1.75 \rho(H+h)}{g} \\
& {\left[\frac{\frac{4 R}{\pi} \cdot \frac{1}{\sqrt{2 H \delta+\delta^{2}}} \cdot \frac{H}{H+\delta}\left\{\frac{2 R}{\pi} \cos ^{-1}\left(\frac{H}{H+\delta}\right)+H+h\right\}}{\left\{\frac{4 R}{\pi} \cos ^{-1}\left(\frac{H}{H+\delta}\right)+H+h\right\}^{2}} \dot{\delta}^{2}\right.} \\
& \left.+\frac{\frac{2 R}{\pi} \cos ^{-1} \frac{H}{H+\delta}}{\frac{4 R}{\pi} \cos ^{-1}\left(\frac{H}{H+\delta}\right)+H+h} \ddot{\delta}\right] \text {. }
\end{aligned}
$$

The wave crest impact pressure does not reach the maximum at the moment when the crest hits
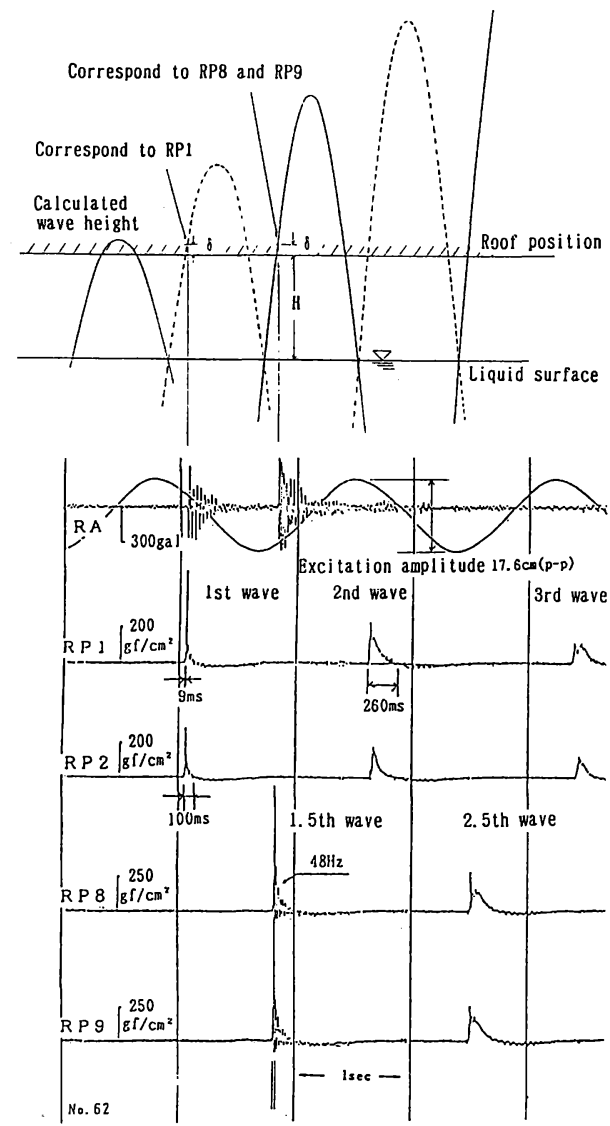

Fig.9 Examples of waveforms (medium-scale model, top space height $27 \mathrm{~cm}$, excitation amplitude 8.8 $\mathrm{cm})$.

the roof $(\delta=0)$. Furthermore, when the wave height becomes the highest without roof, the velocity becomes zero, i.e., $\delta=0$. Therefore, actually, when $\delta$ assumed wave height has become a little higher than the roof, the largest pressure should occur. The pressure waveforms obtained by the experiments show the generated pressure reaches the maximum within $T / 100(T$ : Primary natural period of sloshing).

The sloshing response crest moves in sinusoidal at the same frequency as the sinusoidal excitation force. So, if the circular frequency is $\omega$, and the excitation amplitude is $D$, then the response wave height, $\delta c(N)$, to the sinusoidal excitation force $(N$ wave) and the liquid surface velocity, $\dot{\delta} c$, immediately before collision with the tank roof are evaluated from the following simple equations :

$$
\begin{aligned}
& \delta c(N)=\frac{R D \omega^{2}}{g}\left(\beta_{1} \cdot \pi N+1\right) \cdots \cdots \ldots \\
& \dot{\delta} c=\delta c(N) \cdot \omega \cdot \cos \left(\sin ^{-1} \frac{H}{\delta c(N)}\right)
\end{aligned}
$$


where

$$
\omega=\sqrt{\frac{\lambda_{1} g}{R} \tanh \frac{\lambda_{1} h}{R}}
$$

In case of rectangular tank : $\lambda_{1}=1.571 \quad \beta_{1}=0.811$ In case of circular tank $: \lambda_{1}=1.841 \quad \beta_{1}=0.837$

Hence, if the time at the largest impact pressure is measured and the wave height $\delta$ at the time of the largest impact pressure is obtained from the calculated response wave height $\delta c(N)$ (about twice the top space height ${ }^{18)}$ ), then $\delta$ is recognized to be almost in a range upto $0.1 H$ (Fig.9).

Based on the above discussion of experimental results, we can have $\delta=0.05 H$ as the average value of the wave height $\delta$ caused by the largest crest impact pressure, and also $\ddot{\delta}=\omega \dot{\delta}$ because of sinusoidal motion. Furthermore, since the difference between the crest velocity immediately before collision and the crest velocity at the time of the largest impact pressure is slight, they can be treated as the same. Then, the equation (5) can be simplified as follows :

$$
\begin{aligned}
P= & \frac{6.63 \rho}{g} \cdot \frac{(H+h) R}{H} \cdot \frac{(0.2 R+H+h)}{(0.4 R+H+h)^{2}} \dot{\delta}^{2} \\
& +\frac{0.35 \rho}{g} \cdot \frac{R(H+h)}{(0.4 R+H+h)} \omega \dot{\delta} \cdots \cdots \cdots(9)
\end{aligned}
$$

(2) Comparison of the crest impact pressures estimated by formula with measured

The relation between the impact pressure $P$ and the crest velocity by the estimation formula (9) is shown as solid lines in Fig.5 7. It can be seen that the proposed formula (9) well coincides with the measured values.

The estimation formula (9) indicates that the shorter the top space height $H$ is, the larger the impact pressure $P$ becomes with the same tank dimensions and the same crest velocity, while experimental results also show the same trend.

When the top space is narrow, the data tend to be considerably dispersed. The reason is explained by an assumption that the collision begins before the first-order resonance phenomenon of sloshing is occurred, not allowing the liquid surface form to be approximated by the sloshing mode.

The effect of roof rigidity on the impact pressure is not discussed here. However, since a lower rigidity gives a lower impact pressure ${ }^{18)}$, the application of this proposed formula to a roof of lower rigidity should be conservative.

\section{CONCLUSIONS}

Sloshing experiments were conducted for small-, medium- and large-scale models, using a longperiod large-amplitude shaking table to examine the wave crest impact pressures acting on fixed flat- roofed liquid storage tanks. The conclusions obtained can be summarized as follows :

(1) Since the impact pressure characteristics are non-linear, experiments were conducted using small-, medium- and large-scale models, to examine the scale effect. The effect was taken into account in the estimation formula.

(2) The impact pressure waveform has characteristics peculiar to each specific combination of top space height and excitation amplitude, and can be reproduced.

(3) The sloshing wave crest impact pressure can be approximately estimated by the proposed formula (9) composed of the distance between liquid surface and roof, the radius of tank, liquid depth, the first-order circular frequency of sloshing, and the wave crest velocity at the time of collision.

\section{REFERENCES}

1) Yoshiyuki Yamamoto : Seismic Undulation of Liquid Surface and Impact Pressure in Oil Storage Tanks, High Pressure, Vol.3, No.1, 1965 (in Japanese).

2) Yoshikazu Yamada, Hirokazu Iemura, Shigeru Noda and Saburo Shimada : Characteristics of Relatively LongPeriod Ground Motions Estimated from Oil-Sloshing in Huge Tanks and Earthquake Records, Proceedings of JSCE, No. 362/ I -4, 1985 (in Japanese).

Saburo Shimada, Yoshikazu Yamada, Hirokazu Iemura and Shigeru Noda : Estimation of Long-Period Response Spectra Based on the Non-linear Sloshing Analysis of Cylindrical Tanks, Proceedings of JSCE, No. 368/ I -5, 1986 (in Japanese).

3) Th. von Karman : The Impact on Seaplane Floats during Landing, National Advisory Committee for Aeronautics TN 321, 1929.

4) Wagner, V.H. : Uber die Landung von Seeflugzeugen Zeitschrift fur Flugtechnik und Motorluftshiffahrt, Band 22, Jahrg. 1 Heft, pp.1 12, 1931.

5) Akira Murota and Mitsuaki Furudoi : An Experimental Study, on the Uplifts Acting on the Floor System of Landing Piers, Proceedings of 13th Lecture Meetings on Coast Engineering, JSCE, pp.120-125, 1966 (in Japanese).

6) Kiyoshi Horikawa, Tadahiko Nakao and Akihiro Yajima : An Experimental Study on the Uplifts Acting on Landing Piers, Proceedings of 14th Lecture Meeting on Coast Engineering, JSCE, pp.148-153, 1966 (in Japanese).

7) Yoshizane Aida : An Assumption concerning Impact Wave Forces, Synopses of 22nd Annual Lecture Meeting, Part 2, JSCE, 1967 (in Japanese).

8) Yoshizane Aida : Wave Forces Acting on Structures, Proceedings of 1968 Summer Meeting on Water Engineering, Committee for Hydraulics, JSCE, 1967 (in Japanese).

9) Yoshizane Aida and Shusaku Kakizaki : A Study on Finite Amplitude Overlapping Waves and Their Wave Pressures, Institute for Technical Research of Ports and Harbours, 
5 th Report, No.10, pp.1-57, 1966.

10) Shohichiro Nagai, Tadashi Kubo and Kazuo Tokikawa : A Study on the Uplifts Acting on Landing Piers (No.1), Proceedings of 13th Lecture Meeting on Coast Engineering, JSCE, pp.112-119, 1966 (in Japanese).

11) Ikuyoshi Kuzumi : Experimental Discussion on Wave Dissipating Effect and Wave Forces by Structures such as Estuary Weirs and Bridges, Civil Engineering Information 16-2, Publics Works Research Institute, pp.67-72, 1974 (in Japanese).

12) Yukihiko Ueda : An Experimental Study on the Uplists of Two-Stage Roller Gates, Ishikawajima-Harima Engineering Report, Vol.13, No.6, pp.738-748, 1973 (in Japanese).

13) Kawasaki Heavy Industries, Ltd. : An Experimental Report on the Wave Pressures of Tide Gates, 1981 (in Japanese).

14) Yoshio Ochi and Nobuyuki Kobayashi : Sloshing Experiment of a Cylindrical Storage Tank, Ishikawajima-Harima Engineering Report; Vol.17, No.6, 1977 (in Japanese).

15) Nobuyuki Yoshimura, Toshiaki Tanaka, Yukimitsu Yokoyama, Mamoru Yamamoto and Minoru Oda : A Study of Earthquake-Induced Liquid Sloshing in an LNG Storage Tank, NKK Engineering Report, No.78, 1978 (in Japanese).

16) Osamu Asai, et al. : Proposals for the Earthquake-Proof Designs of Cylindrical Liquid Storage Tank with Fixed Roof (II), Pressure Engineering, Vol.17, No.4, 1979 (in Japanese).

17) Yutaka Hagiwara, Yoshio Masuko and Akio Sakurai :
Summarization of Current Research on Earthquake-Induced Sloshing, CRIEPI Report No.385002, 1985 (in Japanese).

18) Yashiro, T., Kawashima, H., Nakagawa, M., Sakurai, A., Masuko, Y. and Kurihara, C. : A Study on Non-Linear Sloshing of Pool Type LMFBR Coolant, Trans. of the 9th Int. Conf. on Structural Mechanics in Reactor Technology, Vol.E, pp.459-464, 1982.

19) Sakurai, A., Masuko, Y., Ishihama, K., Chang, Y.W., Rodwell, E. : EPRI/CRIEPI Joint Program on Seismic Sloshing of LMR Reactors : Part I -Experiments, Trans. of the 9th Int. Conf. on Structural Mechanics in Reactor Technology, Vol.E, pp.459-464, 1982.

20) Masatoshi Bessho, et al. : A Study on the Longitudinal Motion in the Regular Waves of Express Boats, Proceedings of Japanese Society for Shipbuilding, No.135, 1974, pp.109-120 (in Japanese).

21) Yoshio Masuko, Chizuko Kurihara, Yutaka Hagiwara and Yoshihiro Sawada : Experimental Study on Impulsive Liquid Pressure by Sloshing, CRIEPI Report No.U 88059, 1989 (in Japanese).

22) Werner and Sundquist : On Hydrodynamic Earthquake Effects, Trans. Am. Geophysical Union, Vol.30, No.5, 1949.

23) Editing Subcommittee for JSCE Handbook of Vibration Science : Handbook of Vibration for Civil Engineers, JSCE, 1966.

(Received June 21, 1990)

固定屋根を有する液体タンクのスロッシング 波頭衝撃圧に関する検討

栗原千鶴子・増子芳夫・桜井彰雄

本論文は, 固定屋根を有する液体タンクのスロッシング波頭衝撃圧に関し半実験的評 価式の提案を行ったものである. 本評価式の特徴は, 衝撃圧は波高速度の 2 乗項のみで なく 1 乗項をも含むものである. 衝撃圧は非線形性の強い現象であるため, 実験に際し ては, 小型 (径 $55 \mathrm{~cm}$, 矩形), 中型 (半径 $111.5 \mathrm{~cm}$, 円形), 大型 (径 $670 \mathrm{~cm}$, 矩形) 容器を用いてスケール効果も検討した 